\title{
PROPOSIÇÃO DE UMA ESTRUTURA DE PLANO DE NEGÓCIO PARA UMA EMPREENDEDORA DO RAMO DE BELEZA DA FRONTEIRA SANT'ANA DO LIVRAMENTO/RS - BRASIL E RIVERA - URUGUAI
}

\author{
PROPOSING A BUSINESS PLAN STRUCTURE FOR A BEAUTY \\ ENTREPRENEUR FROM THE FRONTIER SANT'ANA DO LIVRAMENTO/ \\ RS - BRAZIL AND RIVERA - URUGUAY
}

Recebido: 04/10/2019 - Aprovado: 2/12/2019 - Publicado:02/01/2020 Processo de Avaliação: Double Blind Review

\author{
Leonardo Caliari \\ https://orcid.org/0000-0002-0667-7413 \\ Universidade Federal do Rio Grande do Sul \\ leonardocaliari95@gmail.com \\ Fernanda Araujo \\ https://orcid.org/0000-0002-7023-465X \\ Universidade Federal do Pampa \\ fe.gestora@gmail.com \\ Rosemeri da Silva Madrid \\ https://orcid.org/0000-0002-2648-9647 \\ Universidade Federal do Rio Grande do Sul \\ rosemeri.madrid@bol.com.br \\ Sebastião Ailton da Rosa Cerqueira-Adão \\ https://orcid.org/0000-0003-3051-5809 \\ Universidade Estadual de Campinas \\ sebastiaocerqueira@unipampa.edu.br
}

RESUMO: O presente estudo tem o objetivo geral de elaborar uma estrutura de plano de negócio para uma microempresa do ramo de beleza localizada na fronteira Sant'Ana do Livramento (BR) - Rivera (UY). Trata-se de uma pesquisa qualitativa, sendo os dados coletados por meio de entrevistas semiestruturadas e observações e inseridos em um software específico para elaboração de plano de negócio. Como resultado da pesquisa, foi possível edificar uma estrutura de plano de negócio que possibilitou um prédiagnóstico da empresa, a qual possui seus processos de gestão com várias deficiências, especialmente, quanto à gestão financeira. No fim, a estrutura de plano de negócio foi entregue à empreendedora como sugestão para aplicação no seu negócio e, consequentemente, a sua adoção como ferramenta de desenvolvimento.

Palavras-chave: Plano de Negócio; Empreendedorismo; Ramo de Beleza; Região de Fronteira. 
ABSTRACT: The present study has the general objective of elaborating a business plan structure for a beauty microenterprise located at the Sant'Ana do Livramento (BR) Rivera (UY) border. This is a qualitative research, with the data collected through semistructured interviews and observations and inserted in a specific software for elaboration of business plan. As a result of the research, it was possible to build a business plan structure that allowed a pre-diagnosis of the company, which has its management processes with several deficiencies, especially regarding financial management. In the end, the business plan structure was delivered to the entrepreneur as a suggestion for application in her business and, consequently, its adoption as a development tool.

Keywords: Keywords: Business Plan; Entrepreneurship; Beauty branch; Frontier Region.

\section{INTRODUÇÃO}

Empreendedores do próprio negócio tendem a ser mais realizadores do que planejadores. Tal fato é evidenciado principalmente no Brasil, onde planejar não costuma fazer parte da cultura empresarial e o dinamismo econômico torna o planejamento uma atividade vista como burocrática e sem valor por parte dos pequenos empresários. Muitos passam por apuros para articular conceitos de negócios, decorrência da falta de conhecimento e domínio nas técnicas de gestão empresarial (HASHIMOTO; BORGES, 2014).

A consequência do desinteresse e da incapacidade de planejamento é o alto índice de falências de negócios no Brasil durante os primeiros anos de existência (NASCIMENTO et al., 2013; TERRIBILI FILHO, 2014). Dada à relevância das micro e pequenas empresas para o desenvolvimento econômico das regiões, ressalta-se a necessidade de se tentar reduzir os índices de mortalidade empresarial com ações de auxílio e suporte às empresas.

Dentre os ramos que mais crescem quanto a postos de trabalho e distribuição de renda, o ramo da beleza vem tendo destaque no meio empresarial, sendo que, mesmo em meio a um cenário de crise econômica nacional e desmotivação de investimentos, o ramo vem ampliando sua área de atuação. Por exemplo, o setor de franchising no subsegmento de cosméticos e perfumaria registrou um crescimento de 7,7\% em 2015 (SEBRAE, 2017). 
Sendo assim, o objeto de pesquisa neste artigo será uma microempresa do ramo de beleza, localizada na fronteira Sant'Ana do Livramento (BR) - Rivera (UY), o qual será realizado um diagnóstico da empresa por meio de um plano de negócio. Além da importância e força desse ramo na economia, justifica-se o estudo por se considerar relevante pesquisas científicas que produzam resultados aplicados na realidade regional e que impactem em estudos que tangenciem as questões de desenvolvimento local.

Por conseguinte, vale destacar a relação universidades-empresas. Em uma pesquisa da Endeavor, em conjunto com o SEBRAE, que analisou o papel das universidades brasileiras no incentivo ao empreendedorismo, constatou-se que, na visão dos acadêmicos, as universidades fomentam a cultura empreendedora dos alunos, mas pecam ao não oferecer suporte para as empresas se manterem no mercado após o estágio inicial (ENDEAVOR, 2016). Sendo assim, além do propósito acadêmico, o presente estudo busca estabelecer uma relação universidade-empresa, possibilitando suporte ao empresário no que tange ao conhecimento necessário para elaboração de um plano de negócio.

Nesse sentido, tem-se como objetivo geral elaborar uma estrutura de plano de negócio para uma microempresa do ramo de beleza localizada na fronteira Sant'Ana do Livramento (BR) - Rivera (UY). E quanto aos objetivos específicos, pretende-se: caracterizar o empreendedor no ramo de beleza na fronteira Sant'Ana do Livramento (BR) - Rivera (UY); identificar como se dá a gestão do empreendimento do ramo de beleza; sugerir um plano de negócio como ferramenta de desenvolvimento gerencial.

Após apresentada a introdução, passa-se a construção da fundamentação teórica desta pesquisa. No terceiro capítulo, expõe-se a metodologia do presente estudo. Por conseguinte, passa-se a apresentação e análise dos resultados, onde consta a estrutura do plano de negócio propriamente dita. Por fim, destacam-se as conclusões do estudo e as referências utilizadas.

\section{EMPREENDEDORISMO E PLANO DE NEGÓCIO}


Definir um termo é algo difícil e, para uma área de estudos recente como é o empreendedorismo, a tarefa torna-se ainda mais complexa. Tal fato evidencia a inexistência de um consenso acerca da definição dos termos empreendedorismo e empreendedor (BARON; SHANE, 2007).

Em uma abordagem de gestão de negócios, estudos sobre empreendedorismo buscam compreender como oportunidades de criação de novos produtos ou serviços surgem e são descobertas por pessoas específicas, os empreendedores. Essas pessoas, então, utilizam de diferentes meios para explorá-las ou desenvolvê-las, produzindo assim uma vasta gama de efeitos para a sociedade como um todo (BARON; SHANE, 2007; HISRICH; PETERS; SHEPHERD, 2009; KURATKO, 2016).

Para sintetizar as concepções de empreendedorismo e alguns de seus principais teóricos, foi elaborado o Quadro 1 detalhando as visões de empreendedorismo e empreendedor, possibilitando comparações entre os teóricos de diferentes períodos. 
Quadro 1 - Alguns teóricos e suas concepções de empreendedorismo e empreendedor

\begin{tabular}{|c|c|}
\hline Autor & Concepções de Empreendedorismo e Empreendedor \\
\hline $\begin{array}{c}\text { Richard } \\
\text { Cantillon (1680- } \\
1734)\end{array}$ & $\begin{array}{l}\text { Os empreendedores compram determinados insumos, geralmente agrícolas, do qual } \\
\text { buscam processá-lo e revendê-lo por um preço que lhe proporcione lucros, } \\
\text { assumindo os riscos do processo. }\end{array}$ \\
\hline $\begin{array}{l}\text { Jean B. Say } \\
(1767-1832)\end{array}$ & $\begin{array}{l}\text { O empreendedor transfere recursos de um setor de baixa produtividade para um setor } \\
\text { de produtividade e rendimento superior, assumindo riscos em busca do lucro. }\end{array}$ \\
\hline $\begin{array}{l}\text { Joseph A. } \\
\text { Schumpeter } \\
(1883-1950)\end{array}$ & $\begin{array}{l}\text { O empreendedorismo, a partir da inovação, é o motor do desenvolvimento } \\
\text { econômico, sendo o empreendedor o responsável pela criação de novos produtos, } \\
\text { serviços, insumos, métodos de produção e mercados. O empreendedor gera } \\
\text { desequilíbrios em um sistema econômico equilibrado, e, por meio da inovação, } \\
\text { promove o processo de "destruição criativa", tornando os recursos existentes } \\
\text { obsoletos e provocando a sua renovação. }\end{array}$ \\
\hline $\begin{array}{l}\text { David } \\
\text { McClelland } \\
(1917-1998)\end{array}$ & $\begin{array}{l}\text { A partir do estudo das características comportamentais empreendedoras, diferenciou } \\
\text { indivíduos empreendedores e não empreendedores, sendo que a função de } \\
\text { empreendedor aparenta exigir a tomada de decisão diante de incertezas. Classifica o } \\
\text { comportamento humano em três conjuntos de necessidades: realização, afiliação e } \\
\text { poder. }\end{array}$ \\
\hline $\begin{array}{c}\text { Peter Drucker } \\
(1909-2005)\end{array}$ & $\begin{array}{l}\text { Empreendedorismo não é um traço de personalidade. Empreendedorismo é um } \\
\text { comportamento, isto é, qualquer indivíduo responsável pela tomada de decisões em } \\
\text { contextos de risco e incerteza pode, e deve aprender, a ser empreendedor e a se } \\
\text { comportar de maneira empreendedora. }\end{array}$ \\
\hline $\begin{array}{c}\text { Israel Kirzner } \\
\text { (1930-atual) }\end{array}$ & $\begin{array}{l}\text { Empreendedorismo refere-se ao "estado de alerta" à oportunidades de lucro ainda } \\
\text { não identificadas ou exploradas, sendo que este estado de perspicácia é mais do que } \\
\text { uma vantagem relativa em termos de conhecimento. O empreendedor é aquele que } \\
\text { percebe que uma determinada ideia poderá lhe proporcionar ganhos e se empenha } \\
\text { para desenvolvê-la na prática, ou seja, empreendedorismo está diretamente } \\
\text { relacionado à "ação". }\end{array}$ \\
\hline $\begin{array}{c}\text { Timmons } \\
(1941-2008)\end{array}$ & $\begin{array}{l}\text { Empreendedores são indivíduos que apresentam um conjunto de características, } \\
\text { sendo elas: a) Energia e direção; b) Autoconfiança; c) Envolvimento a Longo Prazo; } \\
\text { d) Dinheiro como medida de desempenho; e) Resolução de Problemas Persistentes; } \\
\text { f) Definição de metas; g) Tomada de risco moderada; h) Lidando com o fracasso; i) } \\
\text { Uso de feedback; j) Iniciativa e busca de responsabilidade pessoal; k) Uso de } \\
\text { Recursos; l) Competir contra normas auto-impostas; m) Locus Interno de Controle; } \\
\text { n) Tolerância à ambigüidade e incerteza. }\end{array}$ \\
\hline $\begin{array}{l}\text { Robert Hisrich } \\
\text { (1944-atual) }\end{array}$ & $\begin{array}{l}\text { O empreendedorismo é um processo de criar algo novo de valor, dedicando seu } \\
\text { tempo e esforço, aceitando possíveis riscos financeiros, psicológicos e sociais, e } \\
\text { recebendo as recompensas de satisfação, independência financeira e pessoal } \\
\text { resultantes deste processo. }\end{array}$ \\
\hline $\begin{array}{c}\text { Kuratko } \\
\text { (1952-atual) }\end{array}$ & $\begin{array}{l}\text { Os termos "empreendedor" e "proprietário de pequena empresa" são constantemente } \\
\text { utilizados como sinônimos, porém o empreendedorismo é mais do que simplesmente } \\
\text { criar um negócio. Os empreendedores se caracterizam pela busca de oportunidades, } \\
\text { aceitação de riscos e dedicação ao defender uma ideia até sua aplicação na prática }\end{array}$ \\
\hline
\end{tabular}

Fonte: Elaborado pelos autores, com base em McClelland (1961); Timmons (1978); Schumpeter (1982); Drucker (2008); Hisrich, Peters e Shepherd (2009); Gianturco (2014); Kurakto (2016).

Percebe-se que há diferentes percepções acerca do significado de empreendedorismo e de empreendedor, no entanto, algumas características, tais como o risco, a inovação e a busca por oportunidades de lucro estão presentes desde os primeiros conceitos, apesar de, em alguns casos, não se complementarem. 
De acordo com Drucker (2008), os empreendedores bem-sucedidos, independente da sua motivação pessoal para empreender, buscam criar valor e, consequentemente, contribuem para o desenvolvimento da região em que vivem, considerando que a mudança possibilita a oportunidade para o novo. Com isso, desde a visão de Schumpeter (1982), que coloca a atividade empreendedora como engrenagem do desenvolvimento econômico, salienta-se a relevância do empreendedor para a economia.

Para Keynes (1972), o desenvolvimento seria o estágio do capitalismo em que os problemas econômicos, tais como desemprego, desigualdade de renda, desperdício dos recursos produtivos, dentre outros, deixariam de existir. A economia, nesse caso, entendida como produção e distribuição de riqueza, seria o meio para se alcançar tal estágio, embora não seja o fim do desenvolvimento, o que no entendimento de Keynes se traduz como se o problema econômico não seria o problema permanente da raça humana. Portanto, para Keynes, o desenvolvimento significaria que desde a sua criação o homem enfrentará seu real e permanente problema: como usar sua liberdade a parte das pressões das preocupações econômicas (KEYNES 1972).

A principal relação de Keynes (1972) com o empreendedorismo é o conceito de "Animal Spirits", no qual referia que estados psicológicos determinantes das expectativas, especialmente no longo prazo, eram de maior importância para o investimento. Isso porque Keynes se refere que, além da causa devida à especulação, a instabilidade econômica encontra outra causa, inerente à natureza humana, no fato de que grande parte de nossas atividades positivas depende mais do otimismo espontâneo do que de uma expectativa matemática. Keynes (1972) argumentava que a maior parte das decisões do empreendedor em fazer algo positivo, cujo efeito final precisa de certo prazo para se produzir, deve ser levada em conta a manifestação do entusiasmo como um instinto espontâneo de agir, comportamento tipicamente associado ao empreendedor.

Ainda na visão keynesiana, o empreendedor procura convencer-se a si próprio de que a principal força motriz da sua atividade reside nas afirmações de seu propósito, por mais ingênuas que possam ser e, para o teórico, a situação política e social tinha uma influência preponderante nas oscilações econômicas e, portanto, no desenvolvimento. Na maioria das vezes, é a intuição que guia alguns aspectos do processo decisório e que guia essa decisão (em empreender) e, dentro do conceito "Animal Spirits", é considerado ainda 
o aspecto emocional como fator determinante na tomada de decisão no empreendedorismo.

De modo geral, sabe-se que as atividades empreendedoras das micro e pequenas empresas afetam significativamente a economia de um setor ou sociedade, visto que constrói sua base econômica e gera empregos e renda para a população (HISRICH; PETERS. SHEPHERD, 2009). Porém, cabe destacar o alto número de empreendedores iniciantes com pouca experiência em negócios, sendo que abrir um empreendimento desprovido de conhecimento gerencial pode resultar no aumento das estatísticas de mortalidade empresarial logo nos primeiros anos de empresa (MISUNAGA; MIYATAKE; FILIPPIN, 2012).

Estudos como os de Machado e Espinha (2005), Nascimento et al. (2013) e Borges e Oliveira (2014) mencionam alguns dos principais fatores causadores do insucesso empresarial dos micro e pequenos empreendimentos. Pode-se classificar os fatores em cinco categorias: fatores macroeconômicos, fatores mercadológicos, estrutura e gestão do empreendimento, questões financeiras e fatores relacionados ao comportamento do empreendedor.

Das razões listadas em diferentes estudos, um dos principais fatores está relacionado às dificuldades do pequeno empresário visualizar o seu negócio como um todo. Geralmente, o empresário possui pleno domínio de certa parte do negócio, mas é totalmente inepto em outras, como, por exemplo, ao ter conhecimento em marketing, mas desconhecer de gestão financeira. Com isso, uma forma de captar todos os aspectos que caracterizam um negócio e traçar um diagnóstico do empreendimento é mediante a elaboração de um plano de negócio, visto que um plano força o empreendedor a ter que conhecer todos os componentes do seu negócio, independentemente da sua área de domínio (HASHIMOTO; BORGES, 2016).

Embora existam críticas à realização de um plano de negócio, por ser considerada uma atividade burocrática e pouco produtiva, se bem elaborado, o plano servirá de auxiliar para a obtenção de resultados dos novos empreendimentos e realização de um diagnóstico do andamento do negócio (SCHNEIDER; BORGES; FREITAG, 2015).

Conceitualmente, segundo Hashimoto e Borges (2014), há várias definições de plano de negócio, porém, de modo geral, há consenso ao conceituá-lo como um método de estruturar as informações de um negócio com o intuito de uniformizar seu 
entendimento, avaliar sua viabilidade de mercado e conseguir apoio/recursos para sua execução.

No Quadro 2 é apresentado o escopo de um plano de negócio, com suas seções e respectiva descrição.

Quadro 2 - Escopo do plano de negócio

\begin{tabular}{|c|l|}
\hline Nome da seção & \multicolumn{1}{c|}{ Descrição } \\
\hline Sumário Executivo & $\begin{array}{l}\text { Resume a ideia do plano, apresentando ao leitor o que ele encontrará na leitura completa. } \\
\text { Reforça os pontos principais da ideia de negócio, tais como a estratégia, a equipe, o } \\
\text { produto, o diferencial, o investimento e o retorno. }\end{array}$ \\
\hline $\begin{array}{c}\text { Descrição da } \\
\text { Empresa }\end{array}$ & $\begin{array}{l}\text { Contém a descrição detalhada do empreendimento, suas estratégias de entrada e } \\
\text { crescimento no mercado, o modelo de negócio, as alianças, os objetivos, a visão e a } \\
\text { missão da empresa. }\end{array}$ \\
\hline Produto & $\begin{array}{l}\text { Descreve o produto ou serviço oferecido, detalhando suas aplicações, funcionalidades, } \\
\text { características físicas, estágio de desenvolvimento, certificações e proteções. }\end{array}$ \\
\hline Marketing & $\begin{array}{l}\text { Apresenta a análise do setor de atuação e do mercado, as avaliaçôes da concorrência, a } \\
\text { estratégia de comunicação e distribuição, a identidade, o posicionamento, a proposta de } \\
\text { valor e os fatores ambientais (internos e externos). }\end{array}$ \\
\hline Organização & $\begin{array}{l}\text { Abrange a estrutura organizacional da empresa, contendo a sua estrutura legal, seus } \\
\text { impostos e tributos, a equipe de gestão, o organograma e as políticas de contratação, } \\
\text { remuneração e retenção de colaboradores. }\end{array}$ \\
\hline Operacional & $\begin{array}{l}\text { Descreve as etapas do processo de implantação, a análise da capacidade, os fluxos } \\
\text { operacionais, o gerenciamento dos estoques, os sistemas de qualidade, as ações de pós- } \\
\text { venda e a infraestrutura organizacional. }\end{array}$ \\
\hline Financeiro & $\begin{array}{l}\text { Contém os pressupostos financeiros, envolvendo questões como o fluxo de caixa, } \\
\text { demonstrativos de resultados, projeções de balanço, modelos de custeio, ponto de } \\
\text { equilíbrio e indicadores de desempenho financeiro. }\end{array}$ \\
\hline Investimento & $\begin{array}{l}\text { Apresenta as necessidades de capital, sua origem, composição acionária, payback, valor } \\
\text { presente líquido, taxa interna de retorno e análise dos investimentos. }\end{array}$ \\
\hline
\end{tabular}

Fonte: Elaborado pelos autores, com base em Hashimoto e Borges (2014).

De modo geral, a estrutura de um plano de negócio segue o escopo apresentado no Quadro 2, sendo realizadas algumas pequenas adequações. O Sebrae, por exemplo, oferece um software de elaboração de plano de negócio com uma estrutura pronta, estando dividido em sete partes: sumário executivo, análise de mercado, plano de marketing, plano operacional, plano financeiro, construção de cenários e avaliação estratégica (ROSA, 2007).

No que se refere ao momento certo de se escrever um plano de negócio, Hashimoto e Borges (2014), citam dois critérios: a) quando os riscos do empreendimento alcançarem um tamanho que seja proporcionalmente alto para o empresário; b) quando se faz necessário convencer algum investidor ou acionista a apoiar o negócio. Fora essas duas ocasiões, não há necessidade iminente de se escrever um plano, pois seria apenas 
uma perda de tempo pelo fato do empreendedor não ter em mãos dados suficientes para sua execução.

A elaboração de um plano de negócio não é a certeza de sucesso, mas aumenta as chances de que isso ocorra, visto que se elabora um detalhamento da empresa e do ambiente que a cerca (TERRIBILI FILHO, 2014).

Identificar as oportunidades, pesquisar a percepção dos clientes quanto ao produto ou serviço oferecido, diagnosticar necessidades de recursos financeiros e analisar a concorrência que já está inserida no nicho de mercado em que pretende ocupar ou está ocupando faz com que a empresa consiga estabelecer metas e antecipar ações (SCHNEIDER; BORGES; FREITAG, 2015).

\section{METODOLOGIA}

Quanto aos procedimentos metodológicos da presente pesquisa, trata-se de uma pesquisa com abordagem qualitativa. Os dados para construção do plano de negócio foram coletados a partir da realização de entrevista semiestruturada, seguindo um roteiro pré-estabelecido, tendo o intuito de realizar um diagnóstico acerca da empresa e do comportamento da empresária.

$\mathrm{Na}$ entrevista, buscou-se a percepção da empreendedora quanto ao próprio negócio, suas ferramentas de gestão e seu planejamento para, a partir dessa percepção, elaborar-se a estrutura de plano de negócio ideal para o empreendimento. Para garantir a sigilo dos dados e da empresa, não será exposto no plano o nome do empreendimento e nem da empresária, sendo denominado apenas como "salão de beleza".

No que tange a análise, os dados coletados durante a entrevista realizada "in loco" na empresa, no mês de setembro de 2018, foram inseridos no software Plano de Negócios 3.0 do Sebrae, sendo que o software segue como base a estrutura descrita por Rosa (2007).

Para encaixar o plano no presente artigo, foi realizada uma compactação do seu conteúdo, além de que foram realizadas algumas pequenas adequações no que tange a estrutura do plano a fim de agrupar seu conteúdo. A estrutura de plano de negócio é apresentada na seção a seguir. 


\section{RESULTADOS}

Neste capítulo, é apresentada a estrutura do plano de negócio elaborado para o salão de beleza, estando esse dividido em seis subtópicos: 1) sumário executivo; 2) análise de mercado; 3) plano de marketing; 4) plano operacional; 5) plano financeiro; e 6) avaliação estratégica.

\subsection{Sumário Executivo}

O presente plano de negócio se refere a um diagnóstico organizacional de um salão de beleza localizado na fronteira entre Santana do Livramento-RS (Brasil) e Rivera (Uruguai). Os serviços oferecidos no salão de beleza são: corte com lavado e escova; progressiva; manicure e pedicure; mechas; hidratação; cronograma capilar; lavado, escova e chapinha; botox capilar; tintura; penteado.

A partir de uma estratégia que foca no equilíbrio entre qualidade e preço acessível, o "salão de beleza" almeja crescimento no mercado de atuação por meio da fidelização dos seus atuais clientes e expansão das estratégias de marketing para captar novos consumidores. Atualmente, o marketing boca-a-boca é o principal meio de divulgação dos serviços e, no contexto local, há uma concorrência de acordo com o estrato social em que o salão se destina, sendo nesse caso as classes C e D. Ainda assim, há possibilidades de crescimento para o salão de beleza, especialmente se observadas as análises de ambiente interno e externo.

O quesito finanças necessita atenção especial, visto que são poucos os controles financeiros executados pela empresária. Tal fato impossibilita os cálculos de indicadores e demais operações financeiras, tais como payback e fluxos de caixa, que possibilitariam um diagnóstico mais preciso acerca do desempenho econômico-financeiro do empreendimento.

De modo geral, o negócio é atrativo e tem possibilidade de crescimento e expansão no setor, sendo necessários alguns ajustes quanto ao controle financeiro para a empresária ter conhecimento da real situação econômico-financeira da empresa e, consequentemente, poder realizar investimentos no que tange a ampliação do negócio. 


\subsubsection{Perfil da empreendedora e do empreendimento}

A proprietária da empresa é natural de Paysandú, capital de um dos 19 departamentos do Uruguai, tem 36 anos e atua no ramo de beleza desde 2012. Começou a empreender motivada pela oportunidade de trabalhar no que sempre almejou. Durante a entrevista, foi possível identificar quatro características empreendedoras, sendo elas, eficiência, autoexigência de qualidade, criatividade e construção de redes de apoio. É notável, também, o constante investimento que a empresária faz em cursos de aperfeiçoamento e atualização profissional.

Dentre as características empreendedoras, a empresária acredita possuir os seguintes atributos: coragem, perseverança, proatividade e resiliência. $\mathrm{O}$ primeiro atributo está relacionado à disposição da empresária em se lançar ao seu projeto, correndo riscos do mesmo fracassar; o segundo está relacionado a sua crença e confiança que o projeto se sustenta no mercado; o terceiro relaciona-se à disposição da empresária em trabalhar em diferentes horários e ambientes, para melhor atender sua clientela e fidelizá-la; o quarto relaciona-se à capacidade da empresária em se reerguer perante os obstáculos que surgem.

A empresária é uruguaia e tem sua empresa estabelecida em Rivera, fronteira com o município brasileiro de Sant'Ana do Livramento. Por esse motivo, ela regularizou sua empresa através do Ministério do Desenvolvimento uruguaio, o MIDES. Motivada pela perda de negócios, por não ter nota fiscal, e pelos amigos que incentivaram que ela começasse a contribuir para sua aposentadoria, em 2018, a empresária passou a contribuir para o "Banco de Previsión Social do Uruguai", através da modalidade de "monotributo". Esse é um regime que beneficia micro e pequenas empresas e se assemelha ao Simples Nacional.

Por ser uma microempreendedora individual, a empresária começou seu investimento com recursos próprios, sem financiamentos externos, nem apoio financeiro de terceiros, nem contou com investimento de sócios. Seu maior capital social é o know how que a mesma possui no desempenho de atuação no mercado. A empresária é jovem, não possui ensino superior e seu conhecimento de mercado é totalmente intuitivo, baseado na própria experiência e nas tentativas de erros e acertos. 


\subsubsection{Postura estratégica: missão, visão e valores da empresa}

- Missão: Prestar um serviço de qualidade e com preços acessíveis, impactando na autoestima das clientes e fidelizando o público feminino que se utiliza do serviço.

- Visão: Consolidar presença no mercado, satisfazendo as expectativas dos clientes.

- Valores: qualidade; acessibilidade; aperfeiçoamento; fidelização.

\subsection{Análise de Mercado}

De acordo com estudo realizado pelo SEBRAE (2017), acerca da profissionalização dos centros de estética, o ramo de beleza possui certas características especiais, tais como as poucas barreiras de entrada aos competidores e a fácil substituição de produtos/serviços. Além disso, algumas estratégias competitivas em serviços aplicáveis ao segmento são: diferenciação, controle de qualidade, procura por clientes de baixo custo e focalização em um mercado-alvo específico.

A clientela que frequenta e busca os serviços oferecidos pela empreendedora é formada por pessoas brasileiras e uruguaias, que chegam até o espaço, em sua maioria, por indicações de outras clientes. As frequentadoras do salão são atraídas pelo fator preço competitivo, aliado ao serviço de qualidade.

Quanto à concorrência, de modo geral, o município de Sant'Ana do LivramentoRS possui 310 cabeleireiros com registros do CNAE e, desse total, 55 são profissionais do gênero masculino e 255 são profissionais do gênero feminino, o que sinaliza um perfil majoritariamente feminino atuando no ramo da estética capilar no município em questão, conforme dados do Portal do Empreendedor (2018).

Esses profissionais se dividem pelo estrato social que atendem em seus respectivos negócios, uma vez que cinco espaços do ramo de beleza e estética tem clientela $\mathrm{A}$, quanto o maior número de empreendedoras do setor de beleza e estética atendem clientela dos demais estratos sociais. Com esse contexto, os maiores concorrentes da microempresária tornam-se os salões de beleza localizados no entorno da sua localização, que atendem a clientela com relativo poder aquisitivo, preocupadas com serviço de qualidade e a utilização de bons produtos, aliado a uma empresa que flexibilize os horários de atendimento. 
Já em relação aos fornecedores, ressalta-se que a empresária opta por comprar de lojas locais de ambos os lados da Fronteira, e de distribuidores que buscaram por ela em seu local de trabalho ou que ela teve a oportunidade de conhecer em eventos da área.

\subsection{Plano de Marketing}

Nessa etapa do plano de negócio, de acordo com Rosa (2007), é realizada a descrição dos principais produtos e serviços, preços, estratégias promocionais, estrutura de comercialização e localização do negócio. No Quadro 3, é apresentada a lista de serviços disponibilizada pela empresa, bem como os preços da prestação dos serviços:

Quadro 3 - Lista de serviços com respectivos preços

\begin{tabular}{|c|c|}
\hline Serviço & Preço (em R\$) \\
\hline Corte com lavado e escova & $\mathrm{R} \$ 48,00$ \\
\hline Progressiva & Entre $\mathrm{R} \$ 120,00$ e $\mathrm{R} \$ 300,00$ \\
\hline Manicure e Pedicure & $\mathrm{R} \$ 36,00$ \\
\hline Mechas & Entre $\mathrm{R} \$ 260,00$ e $\mathrm{R} \$ 340,00$ \\
\hline Hidratação & Entre $\mathrm{R} \$ 60,00$ e $\mathrm{R} \$ 120,00$ \\
\hline Cronograma Capilar & $\mathrm{R} \$ 240,00$ \\
\hline Lavado, escova e chapinha & $\mathrm{R} \$ 42,00$ \\
\hline Botox capilar & $\mathrm{R} \$ 85,00$ \\
\hline Tintura & Entre $R \$ 60,00$ e $R \$ 100,00$ \\
\hline Penteado & $\mathrm{R} \$ 60,00$ \\
\hline
\end{tabular}

Fonte: Dados da pesquisa (2019).

Em uma breve análise dos serviços e seus respectivos preços, vale ressaltar que alguns dos serviços possuem preços em intervalos de variação (entre x e y reais), visto que dependem de alguns quesitos, sendo que o principal considerado é o tamanho do cabelo. De um modo geral, os preços estabelecidos pela empresa podem ser considerados atrativos e justos, tornando-se assim competitiva em relação à concorrência de mercado.

No que tange às estratégias promocionais (divulgação da empresa), tem-se destaque para divulgação boca-a-boca, sendo que é passado de cliente para cliente em uma espécie de "bola de neve" e, com isso, a empresária vai captando novos 
consumidores para seus serviços. Além disso, outro meio de divulgação utilizado pela empresária é a rede social Facebook, visto que nela a empresária apresenta os resultados dos seus trabalhos e promove a sua marca, no entanto, essa divulgação via redes sociais poderia ser melhor trabalhada.

Quanto à estrutura de comercialização e a localização de negócio, ressalta-se que os serviços são prestados nas instalações do salão, estando localizado na Rua Monseñor Vera, em Rivera-UY. O atendimento ocorre de domingo a domingo, sem um estabelecimento de horários, sendo realizado via agendamento prévio.

\subsection{Plano Operacional}

O salão de beleza possui espaço físico limitado, com aproximadamente $7 \mathrm{~m}^{2}$, sendo anexo à residência da proprietária. Esse espaço tem duas cadeiras, sendo que sua capacidade de trabalho é baixa, pois a empresária trabalha individualmente. Exceções a esse caso são os trabalhos de manicure e maquiagem oferecidos por prestadoras de serviços independentes que não possuem local próprio de trabalho, buscando oferecer maior comodidade e conveniência aos clientes. Porém, a empresária não cobra porcentagem das profissionais, nem valor extra dos clientes, o que demonstra uma visão empreendedora, mas certa ingenuidade na gestão.

Na Figura 1 consta o layout do salão de beleza, sendo representada com uma foto das instalações do estabelecimento: 
Figura 1 - Layout do estabelecimento

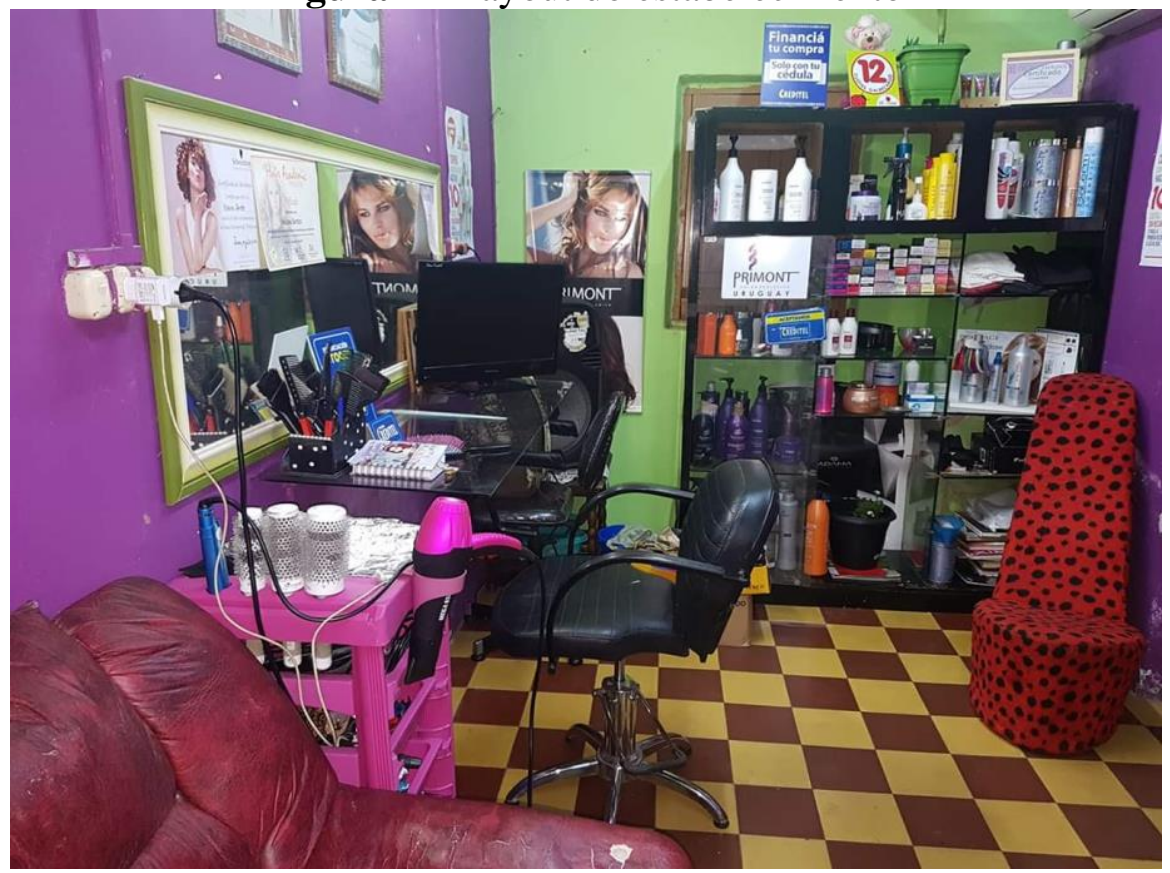

Fonte: Dados da pesquisa (2019).

Analisando a Figura 1, percebe-se a estrutura limitada da empresa que conta com duas cadeiras para atendimento e não tem um layout planejado, ainda que seja notável o esforço em utilizar da melhor forma os recursos disponíveis. O estoque de produtos se encontra no local de atendimento. Não há estrutura de recepção, nem administrativa, todo o espaço é utilizado para atendimentos dos diversos serviços que foram descritos no Quadro 3.

Tal como destacado pelo Sebrae (2018), os processos produtivos de um salão de beleza são divididos em: a) Serviços de Recepção e Atendimento ao Cliente - setor que faz agendamentos e recebe pagamentos de clientes. b) Serviço de Atendimento Qualificado - o profissional com formação e habilidade necessária para prestar serviço especializado. c) Serviço Administrativo - decisões estratégicas tais como contratações e demissões, parcerias com profissionais externos, investimento em publicidade e divulgação, definição dos tipos de serviços e precificação dos mesmos.

No caso deste estudo, a empresária absorve todas as tarefas, estando o fluxo operacional da empresa representado na Figura 2: 
Figura 2 - Fluxo Operacional da Empresa

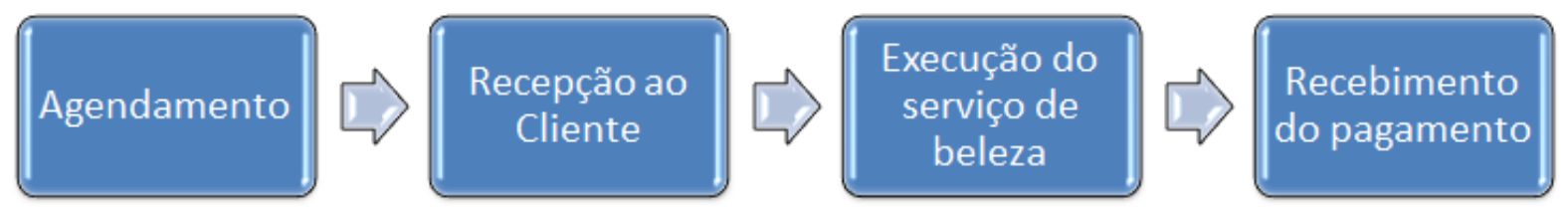

Fonte: Dados da Pesquisa (2019).

Vale ressaltar que todas as atividades expostas no fluxograma são de responsabilidade da empresária, visto que seu trabalho é individual, o que, em alguns casos, pode ser considerado um gargalo quanto à capacidade instalada do salão de beleza.

\subsection{Plano Financeiro}

O plano financeiro traduz, em números, os objetivos, metas e estratégias da empresa. Traz as previsões de quanto que a empresa precisa de capital e como ele será aplicado, das vendas, dos custos, resultados e principais indicadores de viabilidade.

A empresária, através da formalização de seu empreendimento, obteve a possibilidade de trabalhar com cartões de crédito o que permitiu que ela evitasse calotes e oferecesse às clientes a conveniência de pagar os serviços mais caros de forma parcelada. As vendas realizadas através do cartão são o único controle financeiro da empresa, que tem suas finanças confundidas com outros ganhos da renda familiar da empresária.

A realização de controles financeiros básicos é o primeiro passo a ser dado pela empresa para profissionalizar sua gestão financeira. De nada adianta estipular indicadores de desempenho financeiro, payback, vpl, etc., se a empresária não possuir em mãos um controle do que entra e do que sai de recursos na empresa. Nessa perspectiva, tem-se como proposta a utilização de fichas de serviço, para que a empresária possa ter um controle das entradas referentes especificamente ao seu negócio, detalhando o serviço prestado e a data. O modelo da ficha de serviço é apresentado na Figura 3: 
Figura 3 - Modelo de Ficha de Serviço

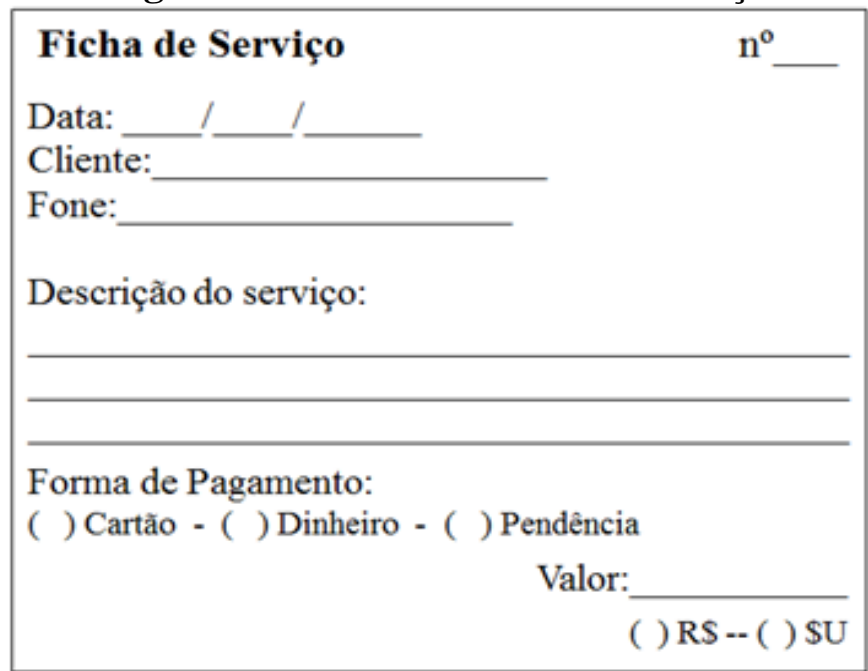

Fonte: Adaptado de Barroso (2018).

Com a ficha de serviço, a empresária poderá ter um controle mínimo de suas receitas, possibilitando que futuramente seja realizado o fluxo de caixa. Porém, para que isso seja possível, faz-se necessário realizar um controle das saídas, que, tal como destacado anteriormente, não possui separação em relação à residência da empresária, o que é considerado um entrave que pode estar mascarando o real desempenho financeiro da empresa.

\subsection{Avaliação Estratégica}

A avaliação da estratégia busca identificar as forças e fraquezas do ambiente empresarial, bem como analisar o cenário externo para listar oportunidades e ameaças que possam afetar o desempenho do negócio (ROSA, 2007). A Figura 4 representa a análise SWOT do salão de beleza, estipulando suas forças, fraquezas, oportunidades e ameaças.

Realizando um breve diagnóstico da análise SWOT, percebe-se que a empresa possui mais fraquezas do que forças, sendo que a maioria dessas fraquezas, por se referirem ao ambiente interno da organização, podem ser controladas e resolvidas pela empresária. Já em relação ao ambiente externo, foi verificado que há mais oportunidades do que ameaças, sendo que a empreendedora poderá ficar alerta a essas oportunidades que proporcionariam crescimento ao seu estabelecimento. 
Figura 4 - Análise SWOT

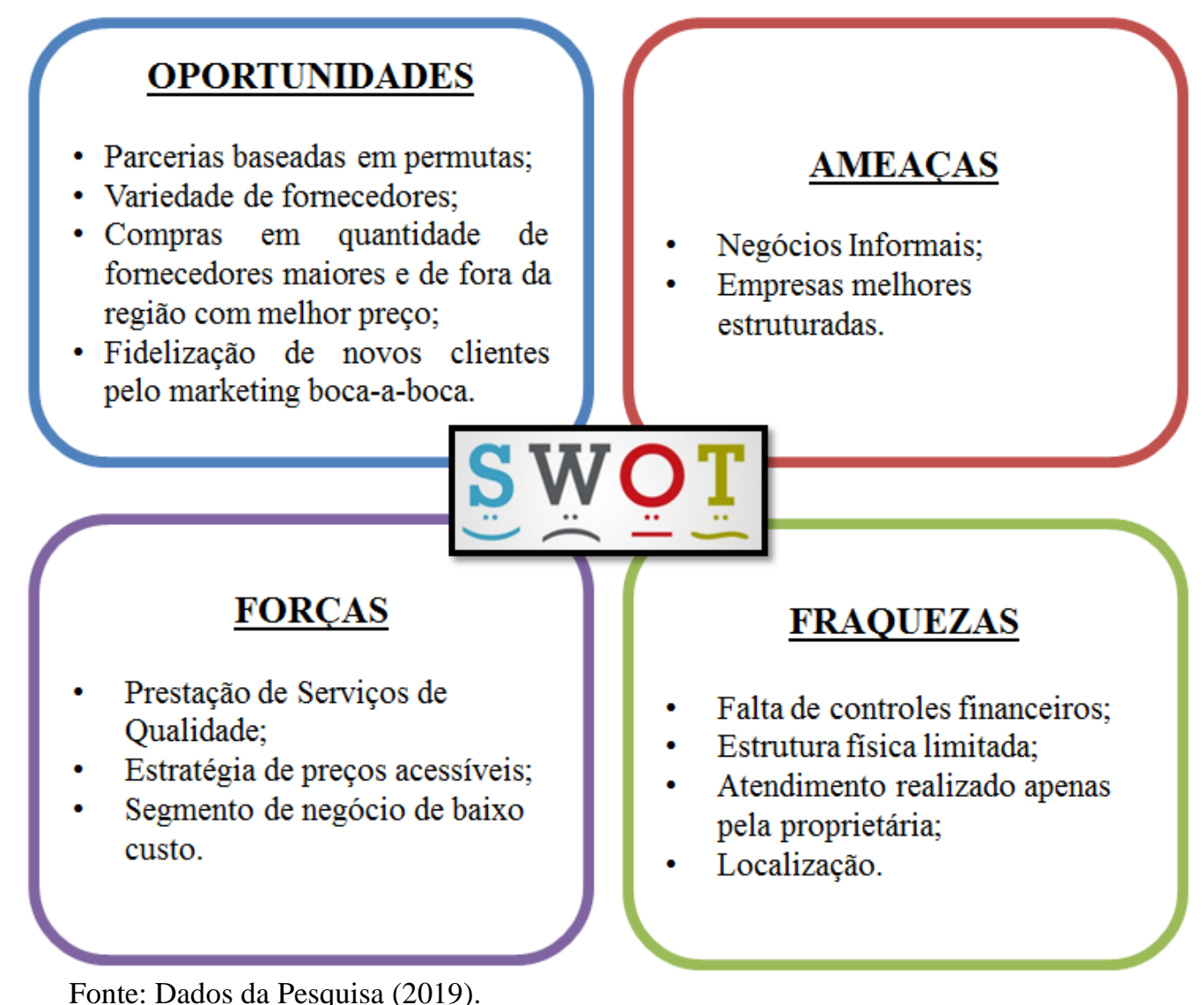

Deve-se destacar que a falta de controles financeiros é a principal fraqueza do negócio. Tal como mencionado por Santos, Ferreira e Faria (2009), dar a devida importância à gestão financeira, especialmente a questão da liquidez, está longe de ser unânime dentro do mercado empresarial, seja pela falta de conhecimento ou pelo descaso por parte de muitos dos pequenos empresários. Além disso, a estrutura física limitada (que impossibilita o crescimento do salão) e o fato do atendimento ser realizado apenas pela proprietária (que faz com que todas as tarefas, desde a recepção e agendamento até o atendimento final ao cliente, estejam centralizadas em uma única pessoa) são outras fraquezas mencionadas. Alternativas para o crescimento do salão seriam a compra de um local (o que não pode ser verificado antes de se realizar os controles financeiros para almejar a viabilidade) ou parceria com algum salão de melhor estrutura para expandir o negócio.

Quanto às forças, vale dar ênfase aos serviços de qualidade por meio de uma estratégia de preços acessíveis, o que possibilita direcionar o foco para um segmento de 
mercado de classes $\mathrm{C}$ e $\mathrm{D}$ e, ao mesmo tempo, fidelizar os clientes pela qualidade do serviço prestado. O fato do segmento de negócio salão de beleza ter um baixo custo, tal como destacado no estudo do Sebrae (2017), faz com que essa estratégia de preços acessíveis seja viável para o estabelecimento, apesar de que sem a realização dos controles financeiros não é possível confirmar se está tendo resultados positivos ou não.

Quanto às ameaças, ambas estão relacionadas à concorrência e remetem-se à estrutura das empresas e aos negócios informais. Sobre a estrutura, já foi evidenciado como uma fraqueza do estabelecimento e, com isso, visto que há uma variedade de empreendedores nesse ramo na região, vincula-se a existência de empresas com melhor estrutura e mais recursos para ampliação. Além disso, negócios informais, segmentados em bairros e pequenas vizinhanças, são ameaças por "roubar" clientes.

Já em relação às oportunidades, destaca-se a questão dos fornecedores, visto que no segmento de beleza há uma variedade de fornecedores e a possibilidade de efetuar compras em grandes quantidades de fornecedores de fora da região e com melhor preço.

\section{CONSIDERAÇÕES FINAIS}

O presente artigo teve por objetivo geral elaborar uma estrutura de plano de negócio para uma microempresa do ramo de beleza localizada na fronteira Sant'Ana do Livramento, (BR) - Rivera (UY). Para alcançar o objetivo geral do estudo, foram elaborados quatro objetivos específicos que serviram como guias para a execução do presente

estudo.

No que se refere ao primeiro objetivo específico, caracterizar o empreendedor no ramo de beleza na fronteira Sant'Ana do Livramento (BR) - Rivera (UY), constatou-se que a empresária do salão de beleza investigado é jovem, começou a empreender por oportunidade, colocando-se como alguém que gosta do que faz e atua em busca de realização pessoal aliada à profissional. É protagonista do próprio negócio, trabalhando sozinha e quanto necessário, chama profissionais como maquiadores e manicures para ajudar na produção.

Quanto ao segundo objetivo específico, identificar como se dá a gestão do empreendimento do ramo de beleza e, através das informações colhidas em entrevista e visita ao espaço de beleza, os pesquisadores constataram a ausência de estratégias de 
gestão. A empreendedora não possui conhecimentos em gestão de negócio, com ausência de controle de custos, estoque, agenda, fluxo de caixa, ferramentas essas que são essenciais para a manutenção do negócio, bem como sua expansão e posicionamento de mercado. A empresa da pesquisada ocupa um espaço físico anexo à residência da mesma e tal como a mistura física entre empresa/casa, detectou-se também a mistura entre as necessidades de insumo do negócio e as necessidades de manutenção da família, contrariando princípios básicos da administração.

Já o terceiro objetivo específico, sugerir um plano de negócio como ferramenta de desenvolvimento gerencial, foi concluído com a elaboração, por parte dos pesquisadores, de um plano de negócio construído a partir das informações disponibilizadas pela empreendedora e também pela análise de mercado local, no segmento de beleza.

Por fim, após responder aos três objetivos específicos da pesquisa, considera-se que o objetivo geral do estudo foi alcançado, visto que, com a elaboração da estrutura do plano de negócio, foi possível realizar um pré-diagnóstico do empreendimento, listando suas potencialidades e limitações. Além disso, com a estrutura do plano de negócio em mãos, a empresária poderá profissionalizar a sua gestão, por meio de adoção de ferramentas eficientes que se utilizadas, podem alavancar o seu negócio, tornando-o mais competitivo e colaborando com a permanência da empresa no mercado.

Como limitações da pesquisa, ressalta-se que não foi possível elaborar o plano de negócio em si, mas apenas uma estrutura de plano a ser entregue à proprietária da empresa, visto que a própria empresária não possuía controle de custos e finanças, impossibilitando a análise da viabilidade do negócio. Outra limitação encontrada pelos pesquisadores foi a escassez de artigos publicados na temática empreendedorismo no ramo de beleza, o que serve de indicativo para novos estudos.

Sabendo da importância das micro e pequenas empresas para o desenvolvimento econômico e a necessidade das universidades voltarem esforços para fornecer suporte técnico, sugere-se que futuros estudos sejam realizados com esse mesmo intuito de proporcionar suporte aos micro e pequenos empresários. Tal suporte se dá no que tange a elaboração de um plano de negócio, seja elaborando um plano completo ou apresentando à empresa uma estrutura para que o proprietário possa se basear durante a realização do planejamento e diagnóstico do seu negócio. 


\section{REFERÊNCIAS}

BARON, R. A.; SHANE, S. A. Empreendedorismo: uma visão do processo. São Paulo: Thomson Learning, 2007.

BARROSO, R. R. L. A Gestão Financeira e sua implicação no Desempenho do Negócio dos Empreendedores no ramo da beleza da cidade de Sant'ana do Livramento/RS / Roseclair da Rocha Lacerda Barroso. Dissertação de Mestrado. Universidade Federal do Pampa. Santana do Livramento. 2018.

BORGES, R. P.; OLIVEIRA, D. M. Sobrevivência e mortalidade das micro e pequenas empresas: estudo dos fatores determinantes e condicionantes. Enciclopédia Biosfera, Centro Científico Conhecer, v.10, n.19, p.508-514, 2014.

DRUCKER, P. F. Inovação e espírito empreendedor: prática e princípios. São Paulo: Cengage Learning, 2008.

ENDEAVOR. Empreendedorismo nas Universidades Brasileiras 2016. 2016. Disponível em: <http://info.endeavor.org.br/eub2016> Acesso em 28 de agosto de 2018.

FILION, L. J. Empreendedorismo: empreendedores e proprietários-gerentes de pequenos negócios. Revista de Administração, São Paulo, v.34, n.2, p. 5-28, 1999.

FONTENELE, R. E. S. Empreendedorismo, competitividade e crescimento econômico; evidências empíricas. Revista Administração Contemporânea, v.14, n.6, 2010.

FRANCO, J. O. B.; GOUVÊA, J. B. A cronologia dos estudos sobre o empreendedorismo.

Revista de Empreendedorismo e Gestão de Pequenas Empresas, v.5, n.3, 2016.

GIANTURCO, A. O empreendedorismo de Israel Kirzner. São Paulo: Instituto Ludwig von Mises Brasil, 2014.

HASHIMOTO, M.; BORGES, C. Empreendedorismo: Plano de Negócios em 40 lições. São Paulo: Saraiva, 2014.

HISRICH, R. D.; PETERS, M. P.; SHEPHERD, D. A. Empreendedorismo. 7.ed. Porto Alegre: Bookman, 2009.

KEYNES, J. M. A Teoria Geral do Emprego, do Juro e da Moeda. Editora Nova Cultural, 1972.

KURATKO, D. F. Empreendedorismo: Teoria, Processo e Prática. 10.ed. São Paulo: Cengage Learning, 2016. 
MACHADO, H. P. V.; ESPINHA, P. G. Reflexões sobre as dimensões do fracasso e mortalidade de pequenas empresas. Revista Capital Científico - Eletrônica, v. 3, n. 1, p. 51-64, 2005.

MCCLELLAND, D. C. The Achieving Society, Princeton: Van Nostrand, 1961.

MINAYO, M. C. S. Pesquisa Social: teoria, método e criatividade. Rio de janeiro: Vozes, 2016.

NASCIMENTO, M.; LIMA, C. R. M.; LIMA, M. A.; ENSSLIN, E. R. Fatores determinantes da mortalidade de micro e pequenas empresas da região metropolitana de Florianópolis sob a ótica do contador. Revista Eletrônica de Estratégia \& Negócios, v.6, n.2, p. 244-283, 2013.

PORTAL DO EMPREENDEDOR. Estatísticas. 2018. Disponível em: <http://www.portaldoempreendedor.gov.br/estatisticas> Acesso em 28 de agosto de 2018.

ROSA, C. A. Como elaborar um plano de negócio. Brasília: SEBRAE, 2007.

SANTOS, L. M.; FERREIRA, M. A. M.; FARIA, E. R. Gestão Financeira de curto prazo: características, instrumentos e práticas adotadas por micro e pequenas empresas. Revista de Administração da UNIMEP, v.7, n.3, p.70-92, 2009.

SCHUMPETER, J. A. A Teoria do Desenvolvimento Econômico: uma investigação sobre lucros, capital, crédito, juro e o ciclo econômico. São Paulo: Abril Cultural (Os economistas), 1982.

SEBRAE. A profissionalização dos centros de estética. 2017. Disponível em: <http://www.sebrae.com.br/sites/PortalSebrae/artigos/a-profissionalizacao-dos-centrosde-estetica,00a9d62b2b886410VgnVCM1000003b74010aRCRD> Acesso em 28 de agosto de 2018.

. Como montar um salão de beleza. 2018. Disponível em: <http://www.sebrae.com.br/sites/PortalSebrae/ideias/como-montar-um-salao-debeleza,42287a51b9105410VgnVCM1000003b74010aRCRD> Acesso em 8 de novembro de 2018.

SRIRAM, V.; MERSHA, T. Entrepreneurial drivers and performance: an exploratory study of urban minority and women entrepreneurs. International Journal of Entrepreneurship and Small Business, v. 31, n.4, p. 514-533, 2017.

TERRIBILI FILHO, A. Escopo de projeto para criação de um plano de negócios. Revista Eletrônica de Estratégia \& Negócios. Florianópolis, v.7, n.1, p.29-55, 2014.

TIMMONS, J. A. Characteristics and role demands of the entrepreneurship. American Journal of Small Business, v.3, n.1, 1978. 